\title{
REFLEXOS DA COMPLEXIFICAÇÃO SOCIAL DECORRENTES DA GLOBALIZAÇÃO À PERCEPÇÃO DAS FONTES DO DIREITO
}

\author{
REFLEXES OF SOCIAL COMPLEXITY DECURRING FROM GLOBALIZATION \\ TO THE PERCEPTION OF THE SOURCES OF LAW
}

Mateus de Oliveira Fornasier*

Data de recebimento: $23 / 02 / 2015$

Data da aprovação: 10/06/2015

\section{RESUMO}

Este artigo analisa alguns pressupostos (relacionados à complexidade decorrente da globalização) que devem ser levados em consideração para que a tradicional teoria das fontes do Direito (relacionada à ideia de soberania estatal) seja reparametrizada, a fim de que o Direito tenha maior efetividade diante de questões relativas à complexidade normativa e à transnacionalização. Nesta senda, a Teoria dos Sistemas Autopoiéticos possui pressupostos derivados das ideias de complexidade, comunicação e extravasamento da estatalidade (sem desconsiderá-la) - sendo que sua observação do Direito em sociedade pode servir de importante substrato para se abandonar um paradigma epistemológico em que a decisão decorra apenas das fontes emanadas do Estado, para se aproximar de um contexto em que a decisão observe comunicações eivadas de sentido jurídico provenientes: de outros Estados, ou de centros emissores internacionais, ou ainda, de centros emissores não estatais. Para sua consecução, serão abordadas considerações acerca dos significados sistêmicos da Política e do Direito - o que significa reparametrizar a própria ideia do que sejam tais sistemas no contexto da globalização. Num segundo momento, tece a possibilidade de considerar

\footnotetext{
* Doutor em Direito (Unisinos), Brasil. Professor da Universidade Regional do Noroeste do Estado do Rio Grande do Sul (Unijuí),

Brasil, Mestrado em Direitos Humanos.

E-mail: mateus.fornasier@unijui.edu.br
} 
uma conversação reflexiva entre fontes provenientes de vários âmbitos normativos da sociedade mundial (ordens jurídicas propriamente ditas), de forma que assuntos que extravasem as fronteiras estatais (no "mundo dos fatos") também o possam ser no mundo do Direito. Por fim, parametriza-se o que significam as "fontes do Direito" a partir da consideração do Direito não mais como estrutura de normas, mas sim, um sistema de comunicações portadoras de sentido jurídico.

\section{PALAVRAS-CHAVE}

Direito; globalização; complexidade; fontes; comunicação.

\section{ABSTRACT}

This article examines some assumptions (related to the complexity resulting from globalization) which must be taken into consideration in order to give new parameters to the traditional theory of the sources of law (which is related to the idea of state sovereignty), so that Law can assume greater effectiveness when faced to issues related to regulatory complexity and transnationalization. In this sense, the Autopoietic Systems Theory has assumptions resulting of the ideas of complexity, communication and extravasation of statehood (without dismissing it) - and its observation of Law in society can serve as an important substrate to abandon an epistemological paradigm in which juridical decision arises only from sources issued by the State, to approach a context in which the decision observe communications characterized by legal sense, which come from: other states, international centers, or even non-state emitting centers. For its achievement, considerations about the systemic meanings of Policy and Law will be addressed - what means the reparameterization of the very idea of what constitutes such systems in the context of globalization. Secondly, the possibility of considering a reflective conversation between sources from various regulatory frameworks of world society (legal systems themselves) is built, so that matters extending beyond state borders (in the "world of facts") also can be in the world of law. Finally, we parameterize what "sources of law" means, from the consideration of the Law not as a framework of rules; rather, it is a system of communications that carry legal sense.

\section{KEYWORDS}

Right; globalization; complexity; sources; communication. 


\section{INTRODUÇÃO}

A dogmática jurídica tradicional tem apresentado respostas que, para questões simples, ocorrentes dentro do âmbito estatal, não apresentam maiores complicações. As teorias da norma jurídica, do ordenamento jurídico e das fontes, conforme apresentadas por juristas da matriz normativista (Kelsen, Bobbio, etc.) são perfeitamente aplicáveis a casos assim, sem carecer de maiores tratativas críticas, muitas vezes (ROCHA, 1999). Contudo, ao se analisarem questões que se complexificam pela sua qualificação em âmbito mundial, nota-se que o normativismo carece de revisitações, críticas construtivas e superações teóricas (ROCHA, 2013).

É bem difundida e conhecida a teoria moderna das fontes de direito, predominante dentre os juristas positivistas. Aprende-se nos bancos acadêmicos que há duas grandes espécies de fonte: imediatas e mediatas. Numa tradição de Direito Romano-Germânica, imediatas são a lei e os costumes; já as mediatas são a jurisprudência e a doutrina. Há ainda aquelas fontes decorrentes da autonomia da vontade individual, pela qual se estabelece parâmetros normativos em caráter privado. Trata-se daquelas que Miguel Reale denomina "fontes negociais", dentre as quais encontramos contratos, declarações unilaterais de vontade (tais como instrumentos de doação, testamentos e promessas de recompensa, dentre outros).

Fontes imediatas têm esse nome em razão de o julgador/intérprete ter de realizar seu julgamento com fundamento nelas diretamente. A lei, em nosso Civil Law, seria, portanto, a fonte máxima, decorrente da ação do Poder Legislativo do Estado soberano, que após projetar, deliberar e aprová-la mediante procedimentos constitucionalmente fundamentados e previamente estabelecidos, confere-lhes validade (e, na maioria dos casos, eficácia). Já os costumes não se originariam de um processo legislativo bem definido em origem, meio e fim. Usos e costumes teriam origem na própria socialização e vivência dos grupos sociais, os quais, em contato direto com as necessidades reais, vão solidificando, em suas condutas, normatividades mediante as quais se pautam cotidianamente.

Apesar de, historicamente, os usos e costumes terem tido importância originária cabal - dado que, principalmente até o Medievo, a lei era, na maioria das vezes, a redução a escrito de costumes já cristalizados em uma comunidade de súditos -, com o advento da Modernidade e os movimentos de codificação inspirados nos ideais de racionalidade e sistematização das Luzes, os usos e costumes vão perdendo, na maioria dos ramos do Direito, aplicabilidade prática. Isto porque facilita em muito a governabilidade pelo Estado quando este formula e impõe a norma a ser aplicada de 
modo uniforme em todo o seu território.

Fontes mediatas, apesar de não serem fundamentos últimos da decisão (ou seja, alguém não será condenado ou absolvido com base em um dispositivo que se assente apenas em uma posição doutrinária ou em um precedente jurisprudencial no sistema Romano-Germânico), possuem a importante função de orientar o posicionamento do julgador em casos nebulosos na interpretação da lei. Seriam, portanto, instrumentos em que o juiz pode se pautar na decisão por uma ou outra norma aplicável a um caso; ou então, em situações em que os termos pelos quais uma norma é expressa são por demais ambíguos - em decorrência da textura aberta da norma -, o juiz se valeria de doutrina e/ou jurisprudência para melhor definir que definições podem ser aplicáveis a um caso em apreço; dentre outros exemplos elencáveis.

Porém, observe-se que, sendo este tipo de teorização acerca das fontes de direito relacionada diretamente ao positivismo jurídico, toda e qualquer fonte de direito depende do Estado para ser considerada como contendo normas jurídicas propriamente ditas. Quanto à lei, não há o que discutir acerca disso, pois é oriunda da atividade do Legislativo e, para certos aspectos regulamentadores, de órgãos e entes executivos. Já os costumes, mesmo que não sejam oriundos da atividade estatal, apenas possuem valor jurídico se aceitos pelo Estado mediante julgamento pelo Judiciário estatal, ou, de modo menos direto, quando não contrariam nenhuma lei estatal (costume ad legem). A jurisprudência é oriunda diretamente de órgão estatal judiciário. E a doutrina, apesar de possuir uma liberdade de posicionamento muito maior, só ganha relevância, na prática, quando considerada instrumentalmente para um julgamento realizado pelo Judiciário, ou argumento importante para a formulação de uma nova lei.

Fontes negociais, nesta mesma senda, apesar de oriundas da autonomia normativa que os entes privados possuem, só são juridicamente válidas quando não ofendem leis estatais. Ademais, a constitucionalização do Direito Privado permite que o Estado (mediante princípios contratuais inseridas em suas leis e o dirigismo dos seus juízes nas revisões contratuais) relativize até mesmo a autonomia privada.

Contudo, que o advento da globalização traz em seu bojo uma série de aspectos que denotam a crise do modelo estatal. Surgem relevantes novos atores internacionais - desde organizações internacionais de caráter publicista tais como ONU, OMC e OIT, passando-se por organizações privadas de padronização da produção técnica (principalmente a ISO), de regulamentação do esporte (COI e FIFA), ONGs e movimentos sociais de âmbito mundial (Greenpeace, Anistia Internacional, WWF, Via Campesina) até empresas transnacionais de amplo alcance global e poder nor- 
mativo. Estes novos atores desafiam o modelo de sociedade internacional solidificado na Paz de Vestfália (1648), fazendo com que, ao lado do Estado, se coloquem outros órgãos de muita atuação transfronteiriça e capacidade comunicativa.

Isto, ao lado de uma outra série de fatores elencáveis, denota que a ideia de fontes de direito deve passar por uma revisitação. Não se trata de acabar com a ideia de fontes, mas sim, reconcebê-las teoricamente, pois a teoria positivista, dependente demais da ideia de Estado, também sofre reflexos da situação da crise da ideia de Estado.

É em razão disto que o presente trabalho se ocupa: da busca por uma nova teorização da ideia de fontes. E, sendo a comunicação e a complexidade tônicas deste novo estado de coisas, escolheu-se, para tal, um referencial oriundo, principalmente, da Teoria dos Sistemas Autopoiéticos (TSA). O presente artigo, nesta senda, tem como diretriz fundamental o seguinte problema: que pressupostos, relacionados à complexidade decorrente da globalização, devem ser levados em consideração para que a tradicional teoria das fontes do Direito (vinculada à e decorrente das ideias de soberania e territorialidade estatais) possa ser reparametrizada, de forma que a decisão judicial possa ser efetiva diante de questões pelas quais perpassem as ideias de complexidade normativa e transnacionalização?

Em relação a este problema, apresenta-se a hipótese de que a Teoria dos Sistemas Autopoiéticos (Luhmann, etc.) possui parâmetros teóricos - ligados à ideia de complexidade, comunicação e extravasamento da ideia de estatalidade (sem a relegar à desimportância) - cuja tomada em consideração pode servir de importante substrato para se abandonar um paradigma epistemológico em que a decisão se ligue apenas às fontes emanadas do Estado (ou de um Estado), para se aproximar de um contexto teórico em que a decisão judicial possa observar comunicações eivadas de sentido jurídico provenientes de outros Estados, ou de centros emissores internacionais, ou ainda, de centros emissores não estatais, sem que se perca a importância da soberania de cada Estado.

O objetivo geral deste trabalho é a análise daquilo que a Teoria dos Sistemas Autopoiéticos, principalmente, pode oferecer para a reconsideração da ideia de fonte de Direito. Para a consecução deste objetivo geral, primeiramente, serão abordadas considerações teóricas acerca daquilo que significam a Política e o Direito como sistemas funcionalmente diferenciados na sociedade mundial - o que significa reparametrizar a própria ideia do que sejam o Direito e a Política no contexto da globalização.

Num segundo momento, passar-se-á a tecer a possibilidade de fazer fontes provenientes de vários âmbitos normativos da sociedade mundial (ordens jurídicas 
propriamente ditas) entrarem em processo de conversação, de forma que assuntos que extravasem as fronteiras estatais (no "mundo dos fatos") também o possam ser no mundo do Direito.

Por fim, passa-se a reparametrizar, de modo propriamente dito, o que significam "fontes do Direito" a partir da tomada em consideração do Direito não mais como estrutura de normas, mas sim, de comunicações de sentido jurídico. Far-se-ão adequações à teoria das fontes, para que não mais se confundam Direito e Política, de modo a se fazer observar que a comunicação jurídica, por mais que observe também a comunicação proveniente da Política (leis, tratados, etc.), confere sentido jurídico próprio a cada uma dessas comunicações.

\section{O DIREITO NA SOCIEDADE MUNDIAL}

A diferenciação funcional, caracterizadora da sociedade desde o advento da modernidade, acaba com a visão monofacetada que, desde os idos de Aristóteles, vicia a teoria social (LUHMANN, 1990, p. 175). Em razão disto, urge a necessidade de mudança na sua observação - o que redunda no delineamento da Teoria dos Sistemas Autopoiéticos luhmanniana. Uma sociedade não pode ser caracterizada conforme uma pretensa "parte mais importante" que a constitua (e. g. sua organização política, sua configuração religiosa, seu sistema de produção). É a forma de organização da diferenciação dos seus vários sistemas comunicativos (modo primário de diferenciação interna) o parâmetro fundamental para caracterizá-la. Em outras palavras: o modo pelo qual uma sociedade constrói seus subsistemas e repete esta distinção em relação ao seu ambiente o fio condutor desta caracterização (LUHMANN, 1990, p. 177). A partir desta forma de estudo da sociedade é possível definir-se o tipo de complexidade com a qual uma sociedade é capaz de lidar.

Neste sentido, sociedades pré-modernas (tradicionais) foram aquelas que evoluíram a partir de diversos âmbitos regionais, tendo seus estratos sociais principais (aristocracias, nobrezas) se fundamentado principalmente nos parâmetros da localidade da propriedade fundiária e/ou da cidade. Assim, reconhece-se na territorialidade como sendo o elemento delimitador da divisão do mundo em diversas sociedades coexistentes (e, de certa forma, cônscias umas das outras), separadas por fronteiras geográficas. Já as sociedades modernas são pautadas pela diferenciação funcional. Isto significa que é a função que cada âmbito social (comunicativo, portanto) exerce (e não mais seu grau de importância na escala social) o princípio dominante no sistema social a partir da modernidade. Esta configuração resulta num 
sistema multifacetado não hierárquico, em que cada subsistema é definido principalmente por sua função e código próprios. Com isto, cada subsistema comporá o ambiente do outro. A funcionalidade, portanto, substitui a territorialidade com o advento da modernidade.

Alguns subsistemas - notadamente a Política e o Direito - continuam a se referir à territorialidade, pois a divisão em fronteiras estatais ainda é considerada uma parametrização útil para a consecução de suas funções; já outros (e.g. Ciência e Economia), se espraiaram globalmente, conferindo pouca (ou nenhuma) consideração as às fronteiras territoriais (LUHMANN, 1990, p. 178). Torna-se cada vez menos possível, assim, limitar a sociedade como um todo pelo critério territorial. Com isto, tem-se que tratar acerca de "sociedades modernas", no plural, também passa a ter cada vez menos sentido. Atinge-se uma situação, assim, em que a única "fronteira" importante é estabelecida pela diferença de configuração comunicativa. Nem ao menos as diferentes formas de produção de capital, ou os diferentes graus de desenvolvimento nos mais diversos países fornecem parâmetros suficientemente convincentes para a distinção de sociedades diferentes.

A inclusão de todos os comportamentos comunicativos em um único sistema social é a consequência inevitável da diferenciação funcional - com isto, a sociedade se torna um sistema global. Todas as formas de comunicação (dotadas de sentido) são incluídas no sistema social global. A sociedade (no singular) é global, então, por duas razões (LUHMANN, 1990, p. 178): a) estabelece-se um único mundo para um único sistema (social, no recorte mais amplo); b) todos os horizontes de sentido são integrados como sendo horizontes de um único sistema comunicativo.

A convergência das inclusões estrutural e fenomenológica é explicada pela complexidade: a pluralidade de mundos possíveis, se tornando inconcebível na atualidade, passa a constituir um único mundo que inclui todas as possibilidades.

No atual estado de coisas, importa muito mais estabelecer "fronteiras" diferenciais entre os mais diversos sistemas e seus ambientes do que buscar eventuais identidades importantes (e. g. a pertença à mesma nação). Isto porque a sociedade moderna é compatível com qualquer forma de diferença de condições de vida, desde que isto não venha a interromper a comunicação. Da mesma forma que a diferenciação funcional substitui a territorialidade, por conseguinte, a identidade também é relegada ao segundo plano: são as distinções funcionais entre sistemas comunicativos autorreferentes e autopoiéticos, e não as identidades entre elementos, que embasam a possibilidade de perceber e processar informação na sociedade global (LUHMANN, 1990, p. 178-179). 
O cotidiano atual demonstra a existência de uma sociedade como sistema global: a mídia, o mercado, os hábitos de consumo, a política externa e a ciência o provam constantemente. Grandes problemáticas inexplicáveis a partir de qualquer regionalidade daí emergem - o ressurgimento (e/ou o fortalecimento) de fundamentalismos religiosos; a substituição do lastro da economia da propriedade pela especulação; a profusão de normas de caráter internacional tratando dos mais variados assuntos; etc. (LUHMANN, 1997, p. 67)

A comunicação, sendo recursiva, exige operações seletivas - que estabelecem diferenças (fronteiras) semânticas relativamente claras. Ambiguidades eventualmente remanescentes podem ser clarificadas mediante o exercício da comunicação. Fronteiras regionais em nada se assemelham a esta qualidade operacional: são apenas convenções políticas, apenas relevantes para a Política e para o Direito na sociedade global - designando apenas locais para a exibição de passaportes e, ocasionalmente, gerar motivos para conflitos: não faz sentido afirmar que separam sociedades (LUHMANN, 1997, p. 73).

O sistema autopoiético da sociedade global pode ser descrito sem qualquer referência a particularidades regionais, dada sua importância secundária para uma teoria sociológica: qualquer teoria deste tipo que busque explanar diferenças regionais não deve introduzi-las como sendo variáveis independentes; devem, isto sim, iniciar pela suposição da existência de uma sociedade global primeiramente, para apenas depois investigar as razões para as tendências à manutenção (ou à acentuação) das diferenças regionais (LUHMANN, 1997, p. 75).

A policontexturalidade decorrente da diferenciação funcional faz desmoronar qualquer garantia de que o desenvolvimento estrutural de um sistema possa continuar compatível reciprocamente entre uns e outros sistemas (LUHMANN, 1997, p. 76). A Ciência não incrementa o poder com o conhecimento, mas sim, expõe os riscos das decisões por ele tomadas; a Economia pode, em parte, considerar lucrativo o uso de tecnologias de alto risco; a imprensa livre transforma a Política numa turbulência de escândalos, revelando hipocrisias- o que leva a uma crítica total da "classe política" (e a um declínio na confiança nela). A nova centralidade dos mercados internacionais financeiros e a substituição da segurança econômica dos patrimônios reais pela especulação leva à perda de empregos, o que seduz políticos a prometêlos. Por outro lado, a "legislatura" das cortes constitucionais afeta a política de uma maneira apenas superficialmente "democrática".

Durante a fase pré-moderna havia uma conjunção desdiferenciada de sentidos políticos, econômicos, jurídicos, morais, científicos, etc. Mas a diferenciação 
funcional acarretada pela Modernidade - decorrente de uma série de processos sociais bastante traumáticos - resultou na autonomização das esferas sociais. Há de se afirmar, contudo, que mesmo essa diferenciação funcional não foi imediata no que tange à relação entre Direito e poder enquanto dominação: apenas a partir do constitucionalismo revolucionário a modernização (enquanto processo de diferenciação funcional) do Direito ocorreu.

A intensificação da diferenciação funcional levou à derrocada da sociedade hierárquico-estratificada anterior. Com isto, a sociedade se torna "multicêntrica" ou "policontextural" - o que vem a significar que: a) a diferença sistema/ ambiente se delineia nos mais diversos âmbitos comunicativos, resultando numa afirmação de pretensões sistêmicas autônomas, distintas e contrapostas; b) toda diferença sistêmica passa implicar uma pluralidade de autodescrições da sociedade, sendo formadas racionalidades diversas, parciais e conflitantes. Isto impede que uma diferença suprema possa se impor contra todas as demais, um "sistema ou mecanismo social a partir do qual todos os outros possam ser compreendidos" (NEVES, 2009, p. 24).

A sociedade moderna surge como sociedade mundial, como formação social desvinculada das organizações políticas territoriais, pois o horizonte comunicacional as ultrapassa (embora o Estado continue a ser uma dimensão fundamental da sua reprodução) (LUHMANN; DE GIORGI, 1996, p. 45-54). Assim, o confluir de comunicações e a estabilização de expectativas se torna cada vez mais regular e frequentemente afastada das identidades nacionais, culturais e das identidades políticojurídicas (NEVES, 2006, p. 217).

Caracteriza a sociedade mundial a conexão unitária da pluralidade de âmbitos comunicacionais simultaneamente concorrentes e complementares. Mas não se pode confundir a sociedade mundial com a ordem internacional, expressão que se refere às relações entre Estados, e que é apenas uma das dimensões da sociedade mundial. Também a controversa noção de globalização não pode ser atribuída sinonimicamente à sociedade mundial, pois se referiria ao "resultado de uma intensificação da sociedade mundial [...], que começou a se desenvolver a partir do século XVI e consolida-se estruturalmente com o surgimento de um 'único tempo mundial' na segunda metade do século XIX", de forma paulatina e irreversível, e que alcança no fim do século XX um grau de caracterização tão elevado que as transformações que se operavam no plano da estrutura da sociedade passam a dominar sua semântica: passa, então, a sociedade a se (auto)observar e (auto)descrever como global (NEVES, 2009, p. 27). 
Não se pode identificar a sociedade mundial com o sistema capitalista mundial, também - em razão do seu caráter multicêntrico (o que oblitera a identificação imediata entre sociedade e economia). Esta sociedade se configura primariamente em função das expectativas cognitivas, havendo, de fato, o primado social do sistema da Economia (NEVES, 2009, p. 28-29).

Assim como no plano estrutural é observável o primado da Economia, semanticamente (ou seja, em sua autodescrição) a sociedade mundial é caracterizada pelo primado dos meios de comunicação de massa, eis que este sistema opera seletivamente frente às várias autodescrições possíveis da sociedade. "Nas mensagens que os meios de massa difundem no dia-a-dia e de fato a fato, cristaliza-se o que, na comunicação societária, é tratado como 'saber" (LUHMANN, 2007, p. 876). Dessa maneira, as informações oriundas dos mais variados sistemas só adquirem significado, pela "opinião pública", mediante o que os meios de comunicação de massa determinam. $\mathrm{O}$ fato de a mídia de massa possuir o primado semântico, contudo, não pode, de forma alguma, ser confundido com a ocupação do centro semântico da sociedade:

A ciência, a educação, a economia etc. não se reproduzem forçosamente pela construção midiática, podendo haver reações "críticas" no interior de cada esfera social aos "absurdos" e "simplificações" produzidas pelos meios de massa. Mas essas reações só serão tratadas como expressão de "saberes" no plano da comunicação societária mais abrangente se forem novamente selecionadas e transmitidas pela mídia. Ou seja, os "saberes" [...]que valem na "opinião pública" produzida e reproduzida pelos meios de massa não se identificam (muitas vezes divergem radicalmente) dos "saberes" [produzidos pelos demais sistemas sociais e veiculados na mídia], embora aqueles predominem sobre esses, constituindo "saberes" da sociedade em contraposição aos "saberes" especializados dos expertos (NEVES, 2009, p. 29-30).

$\mathrm{Na}$ sociedade mundial, os sistemas detentores dos primados estrutural e semântico (economia e mídia de massa, respectivamente) são independentes da segmentação territorial para sua reprodução; contudo, a Política funciona de forma totalmente diversa: sua reprodução ainda é fortemente dependente da divisão em Estados (apesar de se encontrar relacionada ao sistema social mundial): "a dependência entre Estados diminui, mas aumenta a dependência dos Estados com o sistema político da sociedade/mundo" (NAFARRATE, 2004, p. 237). 
Ao Direito, analogamente, podem estas explicações ser aplicadas, eis que "o acoplamento estrutural do sistema político e do sistema jurídico através de Constituições não tem correspondência no plano da sociedade mundial" (LUHMANN, 2004, p. 487-488). Isto denota que, por serem dependentes da segmentação territorial em fronteiras estatais (mormente no que tange à problemática da legitimação), Direito e Política se demonstram relativamente fracos face aos sistemas embasados em expectativas cognitivas que, no plano mundial, conseguem se reproduzir mais intensamente sem a mesma dependência (NEVES, 2009, p. 31).

\section{DO POSSÍVEL DIÁLOGO ENTRE ORDENS DECORRENTES DA PLURALIDADE DE CENTROS EMISSORES DE COMUNICAÇÕES JURÍDICO-NORMATIVAS}

A necessidade de estabelecimento de marcos regulatórios para âmbitos complexos da sociedade mundial (mídia, internet, novas tecnologias, etc.) para a gestão do risco deles decorrentes necessita de respostas que superem a linearidade simplista estabelecida pela segmentação do Direito por fronteiras territoriais. A disposição de parâmetros normativos pressupor um do Direito que ultrapasse a exegese de normas oriundas da lei imposta pelo Estado. Não se trata de minorar a importância da produção normativa estatal, mas sim, buscar uma nova abordagem para a sua existência em um contexto social muito diverso daquele em que sua supremacia se concretizou. $\mathrm{Na}$ atualidade, o tempo de elaboração, votação e entrada em vigor das leis não se mostra tão célere que possa acompanhar o ritmo das transformações sociais, científicas e tecnológicas.

Também a consideração do Direito pelos seus operadores e estudiosos de forma que venha a considerar, de forma simplista e errônea, a ideia da lei (estatal) como sendo eficiente o suficiente para abranger um período de tempo futuro de longa duração, deve ser desmistificada.

[...] Há uma defasagem intensa entre a noção de tempo, a noção de sociedade na dogmática jurídica e o que é a sociedade de hoje. Assim, há um terrível paralelismo temporal, pois os juristas programam normas para durarem anos, e elas não duram, às vezes, dias (ROCHA, 2003, p. 197).

Um esforço de teorização do Direito que evite a defasagem temporal da dogmática jurídica (que se traduz na sua não operacionalidade) deve, assim, ser empreendido. A construção teórica e sistêmica de abordagens dialogais entre ordens 
jurídicas encontráveis na sociedade global deve ser ressaltada. ${ }^{1}$ A maneira pela qual o Direito se (re)configura na realidade globalizada se relaciona com a expansão das possibilidades de escolha proporcionada pelo aumento da complexidade social. Este aumento de complexidade torna muito mais contingentes os contextos nos quais cada subsistema funcional deve operar e decidir. Em razão da multiplicidade de centros de racionalização de sentido neste cenário, pode-se afirmar que, na globalização, não mais se pode atribuir aos acontecimentos sociais uma existência causal unitária. Ademais, a característica fragmentação desta época pressupõe comunicações que ultrapassem as fronteiras territoriais.

O Direito também é afetado por esta fragmentação, de forma que a efetividade do seu funcionamento dependa das suas relações para com os outros subsistemas sociais comunicativos. Em outras palavras, o sistema jurídico (co)evolui com racionalidades diferentes (de outros sistemas sociais), num cenário em que o Estado não é mais o único centro normativo. Emerge, assim, uma pluralidade de comunicadores diferenciados em papéis e culturas, que redunda numa pluralidade de fontes legislativas e atores sociais (dentre eles, novas formas de organização social e política para além do Estado, tais como entes supranacionais) (ROCHA; ATZ, 2010, p. 109).

Neste ínterim, as relações comunicativas se dispersam, viabilizando discursos autônomos e semiautônomos, que concorrem com o sistema jurídico estatal (produtor de sentido jurídico oficial) - cujo monopólio passa a perder a razão de ser numa sociedade sem verdades universalmente válidas e absolutas, quando "os sujeitos observam o mesmo mundo com olhares paralelos" (ROCHA, 2009, p. 12), o que redunda numa situação em que a realidade passa a depender da comunicação de sentido de cada sistema.

Na globalização, rompem-se os vínculos com instâncias centralizadas de poder e processos institucionalizados, eis que se enfraquecem as formas nacionais de identidade cultural (HALL, 2000, p. 115). Assim, a fixação de critérios de validade para o Direito se torna extremamente difícil, havendo, então, mudanças nas expectati-

\footnotetext{
${ }^{1}$ Adota-se, como significado da expressão "ordem jurídica”, o seguinte: "[...] dentro de um mesmo sistema funcional da sociedade mundial moderna, o direito, proliferam ordens jurídicas diferenciadas, subordinadas ao mesmo código binário, isto é, 'lícito/ilícito', mas com diversos programas e critérios. Verifica-se, dessa maneira, uma pluralidade de ordens jurídicas, cada uma das quais com seus próprios elementos ou operações (atos jurídicos), estruturas (normas jurídicas), processos (procedimentos jurídicos) e reflexão da identidade (dogmática jurídica). Disso resulta uma diferenciação [entre ordens] no interior do sistema jurídico, [a qual] não se limita, porém, à diferenciação segmentária entre ordens jurídicas estatais com âmbitos territoriais de validade delimitados. Além disso, não há só uma diferenciação de 'níveis' entre ordem jurídica estatal, supranacional e internacional, mas também a diferenciação funcional de ordens jurídicas transnacionais, desvinculadas, por sua transterritorialidade, do direito estatal" (NEVES, 2009, p. 115-116).
} 
vas - tanto normativas (relacionadas à Política, ao Direito e à Moral) quanto cognitivas (dos sistemas da Economia, da Ciência e da Tecnologia, mormente) (TEUBNER, 2005, p. 115). Esvazia-se então a possibilidade de fixação de um locus único de produção normativa, pois os processos de normatização são diluídos no emaranhado de relações comunicativas da sociedade global, sendo que este poder passa a ser distribuído a vários atores sociais descentralizados (TEUBNER, 2005, p. 114-115). Portanto, em disposição paralela à do Estado, emergem outros produtores de sentido jurídico, desvinculados do Estado (e.g. organização internacionais de normatização de padrões técnicos, sindicatos, comunidades, empresas transnacionais, etc.).

Uma inversão nos processos de formação da nova ordem jurídica (global) ocorre, deslocada dos centros institucionalizados (pela noção de Estado) para a periferia (locais fronteiriços entre um sistema social e outros) do sistema do Direito, onde outras racionalidades jurídicas concorrentes existem (LUHMANN, 1990, p. 160). É justamente para que se superem dificuldades comunicacionais entre periferia e centro do sistema jurídico que devem ser estabelecidos acoplamentos estruturais entre eles - dispositivos estes que viabilizam mecanismos recíprocos de refreamento e equilíbrio, que possibilitem a autonomia dos sistemas acoplados e a ocorrência de influências não deletérias.

A regulação estatal-nacional (ou ainda, entre Estados numa ordem internacional), outrora tida como plenamente satisfatória per se para a resolução dos conflitos jurídicos, não mais se revela suficiente. Exemplos como a lex electronica (regulação jurídica das comunicações no meio eletrônico mundial e adjacências) e a lexmercatoria (regulação, geralmente contratual e de resolução arbitral de conflitos, das relações econômico-empresariais entre empresas transnacionais) demonstram esta problemática, já que nem mesmo o Direito Internacional Público - acometido pela dificuldade de consenso interestatal - parece ser suficiente para tal (ROCHA, 2010, p. 114-115). Os âmbitos comunicativos referentes a estas regulações superam, em muito, a capacidade de abrangência do Estado-nação e de toda forma de normatização a ele referente, por usas próprias características: as comunicações pela internet não conhecem fronteiras, e as empresas transnacionais lhes dão importância secundária (ROCHA, 2010, p. 119).

Um grande desafio com que se depara o Direito global, assim, é a dispersão das fontes - a qual se refere às difíceis questões relacionadas ao fundamento do Direito (ROCHA, 2010, p. 115 e 118). Estas questões, que até então eram respondidas de modos tradicionais (norma hipotética fundamental, regra de reconhecimento, etc.), calcadas na supremacia do conceito de Estado e dos seus postulados, no atual 
cenário devem ser reconcebidas. Uma forma interessante de focar o Direito, portanto, é fundamentá-lo na própria sociedade, deixá-lo permear-se pela influência de outros centros normativos, em uma diversidade social maior do que a estatal. Assim, este deve se comunicar com fontes oriundas de outras ordens, aprimorando seus acoplamentos estruturais também para com os demais sistemas funcionais, a fim de fazer frente à sociedade contemporânea. O pluralismo de centros produtores de normatividade redunda no surgimento de novas formas de regulação normativa - e, neste estado de coisas,

a referência a um Estado, titular singular do poder normativo e garantidor da estabilidade, permite, com efeito, localizar as normas no espaço e inscrevê-las no tempo. Desestatização do espaço normativo e desestabilização do tempo não são próprias da economia, mas da mundialização [...] (DELMAS-MARTY, 2003, p. 72).

A proliferação de normas se traduz num aumento diretamente proporcional de fontes que emanam do contexto complexo da sociedade mundial, conduzindo a uma paradoxal desregulamentação. Um Direito mais "suave" vai sendo delineado, mais flexível e proliferável - o qual pode ser visualizado, e.g., na soft Law, nos direitos híbridos, nos direitos oriundos pura e simplesmente de contratos, no Direito das organizações (DELMAS-MARTY, 2003, p. 73).

A ideia de um pluralismo ordenado surge da coexistência de diversas ordens jurídicas e fontes de normatividade. Torna-se desejável que o Direito seja encarado pragmaticamente, mais adaptado às imposições da existência, pois tem se revelado insuficiente o modelo normativo até então imperante. Isto evoca a necessidade de uma observação construtivista, que supere a insistência de muitos Estados em não aceitar a transformação do Direito - em outras palavras, que relutam em não aceitar o diálogo entre fontes dos mais variados sistemas.

\section{A REPARAMETRIZAÇÃO DAS FONTES A PARTIR DA TEORIA DOS SISTEMAS AUTOPOIÉTICOS}

O operador do Direito deve estar cônscio de que a titularidade jurídica não mais significa a adstrição a apenas uma ordem estatal: a cidadania tem passado a portar sentidos cosmopolitas, o que se vislumbra na análise dos sentidos que a ordem jurídica mundial dos Direitos Humanos passa a dar à própria origem da titularidade (nascer humano no mundo, e não mais cidadão no Estado); a comunicação (em seus 
mais variados sentidos) é cada vez mais global, transbordando as fronteiras estatais. Não se trata de relegar à desimportância os sentidos das operações estatais, mas sim, de fazê-los observarem comunicações de outras normatividades que não as estatais.

Todo sistema é encarregado de uma função, a qual desempenha mediante sua alternância de operações - para o que possui dispõe de um símbolo gerador de sua unidade (LUHMANN, 2005, p. 154). A simbolização, que é uma ficção sistêmica, é o meio pelo qual o sistema produz a continuidade entre suas operações, de modo que referências recursivas são construídas no seu próprio interior. O símbolo do Direito é a validade jurídica (na Economia, é a moeda; na Política, o poder, etc.). A validade é a aceitação da comunicação que permite a autopoiese do sistema do Direito - e o que confere a validade a determinada comunicação (diploma normativo, decisão judicial, etc.) não é sua (pretensa) qualidade intrínseca, mas sim, a referência que o próprio sistema tem sobre tal norma.

A doutrina das fontes de direito se justifica, historicamente, pelas necessidades da(s) época(s) em que o Estado busca se afirmar mediante a positivação do direito em fontes (remetidas, por sua vez, ao Estado) (LUHMANN, 2005, p. 484). Com este processo, comunicações oriundas do sistema político estatal (leis, etc.) adquirem força normativa, em oposição a outras estruturas estabelecidas (tais como a Religião ou a Moral) - conferindo a Política, para si própria, o status de prática contínua de decisões coletivamente vinculantes. Mas na medida em que este objetivo é atingido, também o Direito vai se diferenciando funcionalmente, passando a não mais prescindir da figura do "soberano" para conferir a validade às suas decisões: cada sistema (Política e Direito) decidirá de maneiras diversas (em um caso, pelos Parlamentos, principalmente; noutro, pelos Tribunais).

O conceito de fonte de direito, naquele contexto, possuía vantagens teóricas, pois identificava que comunicações eram juridicamente válidas, relegando à superfluidade qualquer outro questionamento em relação à essência do jurídico (ou, e.g., de delimitação entre direito, moral e costume) (LUHMANN, 2005, p. 597); porém, apenas para o período de transição recém relatado o seu funcionamento é plenamente útil, pois, a posteriori, o sistema do Direito se diferencia daquele da Política.

A ficção jurídica da validade da norma manifesta a impossibilidade de sustentação da validade na própria legislação - e esta constatação impede a absolutização do conceito de fonte (ou seja, uma fundamentação da legitimidade do sistema em algo que não seja um elemento interno ao próprio sistema) (LUHMANN, 2005, p. 156). A figura da fonte passa, portanto, por uma reparametrização quando contemplada a partir do ponto de vista da teoria dos sistemas autopoiéticos: substitui-se 
o seu conceito (como fundamentador da decisão) por aquele que lhe confere relevância jurídica - a validade. Quando seu entendimento se torna comunicação a que o sistema confere validade mediante parâmetros autorreferenciais, permite-se uma visualização muito mais acurada daquilo que o sistema realiza em suas operações a partir daquilo que se denominaria fonte (lei, contrato, etc.).

A interpretação das leis (e sua argumentação) é um problema de fundamentação das decisões oriundas do sistema do Direito (seja na tradição da Common Law, seja na tradição da Civil Law). Nesta senda, legislação é a comunicação oriunda da periferia (política) do sistema, que a este pode irritar - o que será respondido pelo sistema do Direito mediante sua consideração na auto-observação do sistema. De outra banda, contudo, não é o decisor (tomado como "sujeito" singular) quem decide acerca de algo: toda decisão é realizada pelo sistema - o que se pode examinar, num exemplo significativo, na questão da decisão após passar por instâncias recursais: salvo exceções, sempre que uma decisão for proferida, podem ser visualizadas possibilidades de uso da via recursal para sua revisão, em que se argumentará segundo parâmetros do próprio sistema (e não apenas à discricionariedade/arbítrio de $u m$ decisor). Observase, nesta senda, haver "operações do sistema para reduzir o âmbito de escolha das decisões, para quando estas devam ser tomadas" (LUHMANN, 2005, p. 432).

Cabe, portanto, um questionamento neste sentido: deve ser refutado o raciocínio teórico jurídico fundamentado em fontes - e, juntamente com ele, toda teoria (e/ou metodologia) nele embasada -, em decorrência da mudança do foco de observação que a adoção da teoria sistêmica provoca?

Inicialmente, o afastamento da possibilidade de aceitação de uma "teoria das fontes" embasada na legislação não pode ser tornado absoluto. Quando se analisa que a decisão legislativa é tomada no sistema Político, isto não significará uma exclusão teórica absurda da lei do mundo do Direito: apenas se afirma que a decisão resultará da auto-observação do sistema, após ter havido um processo de irritação do ambiente sistêmico (formado por todos os outros sistemas, sociais ou não, inclusive o Político). O fato de o sistema do Direito, a fim de reduzir a complexidade, criar seu próprio ambiente (ou seja, realizar uma observação daquilo que significa o ambiente a partir dos seus próprios parâmetros) não exclui a importância da fonte no processo comunicativo social.

A estes ruídos causados pelo entorno, o sistema responderá, de maneira dialogal, com parâmetros muito mais condizentes com a caracterização de demandas tão complexas quanto as atuais. Ora, não se pode esperar que apenas a atividade legislativa (política) estatal, com todos os seus problemas de tempo de resposta da 
irritação que a sociedade nele produz, seja capaz de responder adequadamente sozinho. Também não se pode esperar que a capacidade normativa do aparelhamento administrativo estatal (comissões, autarquias, conselhos, etc.) seja, por si só, suficiente. A diferenciação funcional da sociedade impossibilita concepções relativas a apenas uma instância normativa omniabarcadora da sociedade.

Com esta impossibilidade faticamente constatável, cada (sub)sistema social operará mediante suas próprias simbologias, ficções: a Política mediante a figura do poder; o Direito, pela figura da validade. É claro que este último poderá conferir validade a vários tipos de comunicação (comunicações realizadas no sistema político, no sistema econômico, etc.); mas é o próprio sistema que confere validade, e não o caráter intrínseco de cada norma (o fato de ser denominada "lei", "decreto", "contrato", etc.).

A adequação do raciocínio das fontes aos parâmetros revelados pela teoria dos sistemas autopoiéticos permite, portanto, uma interessante concepção daquilo que elas sejam: há comunicações do sistema do Direito resultantes das operações sistêmicas decorrentes das irritações da Política (leis), cujo sentido será traduzido, na estrutura e na organização do sistema, conforme a sua autorreferência. Há comunicações que ocorrem também em outros sistemas sociais (como os contratos, no sistema econômico), aos quais o sistema jurídico confere validade, de acordo com seus próprios parâmetros. Há, ainda, comunicações resultantes das operações do próprio sistema (tais como os entendimentos jurisprudenciais precedentes); e há, por fim, a doutrina como sendo parâmetro fornecedor de argumentos de autodescrição do sistema (que, muitas vezes, incorpora argumentos oriundos da ciência, da filosofia, etc.) - a qual, ao ser reiteradamente utilizada como parâmetro para argumentação, adquire o símbolo de validade.

A decisão acerca de quais são as fontes a serem utilizadas em uma argumentação dependerá do raciocínio acerca da validade dos argumentos delas oriundos: não se está aqui postulando, por exemplo, a possibilidade de se fundamentar uma decisão a partir de argumentos fundamentados em "fontes" cujos sentidos não possuam validade para o sistema. O diálogo que se está buscando construir (e defender) no presente trabalho é resultado da auto-observação do sistema, de acordo com sua autorreferência, a qual depende da consideração da validade dos argumentos. Não se intenta, aqui, defender a possibilidade da simples inserção de elementos estranhos a uma ordem jurídica no seu bojo: busca-se, isto sim, afirmar haver a possibilidade de se reconstruir, a partir dos parâmetros programáticos de cada ordem, aquilo que cada ordem jurídica possa observar em outras. Caso não 
seja possível, em hipótese alguma, esta reconstrução que é, na verdade, uma autoconstrução decorrente da provocação proveniente do entorno, o próprio sistema, de maneira argumentativa dialogal, irá refutar.

\section{CONCLUSÃO}

Num ambiente complexo, o sentido do jurídico deve ter sua compreensão reformulada de acordo com ideias menos simples, menos lineares. Se por um lado a aplicação linear exige um raciocínio legal-isolacionista - no tocante ao texto que deverá ser aplicado em concomitância ao afastamento de vários outros -, o cenário hipercomplexo deverá compreender haver a possibilidade de existência de vários textos a serem aplicados, a depender da complexidade do caso concreto. A busca pela simplificação de uma realidade dotada de um potencial hipermutável e hiperimprevisível num mero texto legislativo de pretensões omniabarcadoras esconde, em si, a existência de um descompasso entre a realidade da sociedade cujas expectativasnormativas serão reguladas pelo sistema do Direito e as propostas tradicionais de regulação ainda em voga na práxis regulatória.

O que se busca aqui é apontar para a necessidade de uma nova maneira de visualizar o problema, não mais dividindo-o "em tantas parcelas quantas fosse possível e necessário para melhor [resolvê-lo]", para depois proceder "começando pelos objetos mais simples e mais fáceis de conhecer, para subir pouco a pouco, como degraus, até o conhecimento dos mais compostos e supondo certa ordem mesmo entre aqueles que não se procedam naturalmente uns aos outros", e concluir "fazendo enumerações tão completas, e revisões tão gerais" que seja possível nada omitir (DESCARTES, 1996, p. 23). É em oposição a visões simplistas e exageradamente aplicadas de seus postulados metódicos na prática (e na compreensão do Direito) que se busca visualizar o Direito como sistema social, com toda a complexidade que sua operatividade reflexiva e autopoiética lhe caracteriza.

Instrumentos normativos estatais capazes de açambarcar alguns aspectos da vida social já existem e vigoram nas ordens estatais - seja em suas Constituições, seja em suas legislações ordinárias, seja em normativas expedidas pelos seus órgãos administrativos. Apesar de estarem divididos em "compartimentos", numa pretensão ramificadora do Direito, são dotados de sentidos, que podem ser, de maneira dialogal, coordenados de maneira a melhor expressarem a pretensão normativa que os representantes de determinada sociedade para um caso em concreto. Assim, nem sempre são necessárias mais leis, pois há grande potencialidade de se 
buscar nos enunciados já existentes (em âmbito mundial) o sentido normativo que se busca para as condutas.

Há comunicações interestatais e supraestatais (que dependem da figura do Estado para terem validade - na ratificação de tratados, principalmente) com sentidos normativos, mas que podem ser invocadas mesmo contra a atuação antijurídica daqueles que venham a promulgá-las. Para além disto, pode-se entender que ao pactuarem normas desta forma, estão não apenas se autolimitando, mas também criando, para si e para os cidadãos sujeitos às suas ordens, compromissos de inclusão social - os quais podem ser entendidos não apenas como parâmetros para julgamento, mas também fundamentos invocáveis na construção do sentido jurídico de maneira dialogal. Em outras palavras: tratados, como os que versam sobre Direitos Humanos, devem ser vistos como dotados de caráter obrigatório, não como meras recomendações para um futuro distante.

Os sentidos normativos, no atual cenário da sociedade mundial, sequer dependem integralmente da figura estatal. A tendência de descentralização normativa da sociedade mundial configura, de modo centrífugo, centros emissores de normas para a periferia do sistema. Assim, empresas transnacionais, de abrangência muito maior do que o âmbito que as fronteiras estatais delimitam, possuem ordenamentos contendo sentidos normativos - e, mediante seus contratos e soluções de conflitos deles oriundas, está se conformando uma verdadeira nova lex mercatoria. O mercado de trabalho se autorregula mediante normatizações oriundas de negociações entre empresas e sindicatos (ambos entes privados). Os esportes apresentam centros de emissão normativa, respeitados, a depender do caso, em âmbito mundial. A própria rede mundial de computadores possui seus centros emissores de decisões e normas. E, por sim (mas numa lista não estanque), há organizações que emitem comunicações normativas de padronização técnica (como a ISO) dotadas de sentido normativo.

Toda comunicação é social, antes mesmo de se tornar jurídica (TEUBNER, 1989, p. 164). Em relação a esta constatação, uma analogia poderia ser feita: toda comunicação dotada de caráter jurídico pode adquirir validade, mesmo que os "filtros" ligados à soberania estatal façam muito do sentido se perder quando se passa de um sistema a outro. Este postulado, muito ligado à questão da interferência intersistêmica (a qual é notadamente fundamentada naquilo que os sistemas econômico e jurídico possuem em comum nas suas comunicações), permite que se visualize uma possível articulação dialogal entre as mais variadas ordens normativas. Em outras palavras: pode-se falar de uma confluência de sentidos entre uma ordem normativa (estatal, internacional ou não estatal) para com outra(s) (que podem ser, igualmente, 
dos mais variados tipos e níveis) - e, nessa confluência de sentido, possibilidades de diálogos transordinais podem ser encontradas.

Eis o raciocínio acerca do diálogo, portanto: o sentido do jurídico é o mesmo em toda ordem jurídica funcionalmente diferenciada, conforme a teoria dos sistemas: código e programa; fechamento operativo e abertura cognitiva; unidade da diferença; são todas categorias que possibilitam analisar qualquer ordem dessa natureza, não importando quais sejam os programas no momento do diálogo. As observações mútuas entre comunicações provenientes de diferentes ordens (que aqui, num neologismo possível, são denominadas transordinais) são visualizáveis nesta estruturação global do sentido jurídico - observações estas que, ao operarem (e operam, por mais lentas que sejam!), demonstram a reflexividade de cada ordem de maneira metaforicamente similar a um ciclo de reações que não conhece fronteiras para além daquelas que versam sobre o sentido jurídico.

Apenas mediante a percepção da dupla contingência entre sistemas é possível o estabelecimento do diálogo entre ordens jurídicas. Ora, diálogo pressupõe dois polos diferentes como ego e alter, os quais, em observação mútua, podem chegar a uma racionalidade transversal (alter ego) que permita uma provável (mas não necessária) coligação entre ambos. Ao observar o funcionamento de outra ordem jurídica, um determinado sistema pode se aperceber daquilo que no outro há de conforme ao seu próprio funcionamento - sendo que, assim, sem desrespeitar sua operatividadeautopoiética, um sistema aprende com o outro (e não simplesmente refuta ou transplanta de maneira, talvez, corrupta, a informação oriunda do outro).

Se a disposição sistêmica dos vários níveis, ordens e sistemas jurídicos da sociedade mundial permite observar que toda comunicação jurídica o é antes ainda de ser estatal; e se a dupla contingência permite visualizar possibilidades dialogais entre ordens; e se já se percebe (como variação já, talvez, um pouco selecionada, no sentido teórico-evolutivo) na práxis judicial vários exemplos de diálogo das fontes, de transconstitucionalismo e de utilização de decisões de outras ordens como ratio decidendi (operada, reitere-se, de maneira que não desrespeita a autopoiese dos sistemas), pode-se conceber o início de uma nova maneira de se conceber o mundo do Direito na sociedade mundial: uma percepção complexa, que refute o meramente linear omniabarcador em situações em que isto não seja adequado.

A Teoria do Direito necessita de visões transordinais (visões "entre ordens", já que se trata de valorizar diálogos entre várias ordens jurídicas, ou níveis de organização jurídico-comunicativa na sociedade mundial): observar o outro; observar para não meramente absorver; observar para conceber, de maneira "alteregoística" (dia- 
logal, para não se ater apenas a neologismos) um Direito complexo para problemas complexos. O diálogo entre várias ordens numa dada exigência complexa de "arrolamento de ordens possíveis de serem utilizadas" já representa um passo para além da mera disciplinaridade (consideração de que só há uma possibilidade de sentido jurídico, estatal) e da pluridisciplinaridade (possibilidade de reconhecimento de que vários centros podem emitir sentido jurídico na sociedade). Trata-se da consideração da possibilidade de construção de vias dialogais entre essas ordens.

A ideia de globalização é comumente associada à metáfora de uma "aldeia global", até mesmo por observações relacionadas ao senso comum, na atualidade. Este ideal de aldeia pode sim pressupor uma "fórmula demagógica para esconder uma nova forma de dominação da terra pelos ricos"; porém, numa observação de caráter potencialmente transdisciplinar, pode ser visualizada uma outra extremidade, de "aldeia das aldeias" - na qual haveria possibilidades de acolhimento para a "transreligião, a transcultura, a transpolítica" (NICOLESCU, 2005, p. 92-93). Talvez haja espaço para um Direito transconstitucional (conforme apontou Neves), de onde se pode parafrasear o neologismo transordinal (ora proposto), sendo consideradas as diferenças de sentido, de local, de sistemática jurídica de cada ordem - mas sempre podendo se considerar, cognitivamente, a possibilidade dialogal e de aprendizado entre as ordens, nas auto-observações do Direito.

Sendo assim, o jurista, ao perceber que a complexidade deverá ser reconcebida no funcionamento do sistema do Direito para que as decisões normativas a ela concernentes tenham a possibilidade de concretização de alguma efetividade prático-social, poderá se tornar cônscio de que os problemas que se está por enfrentar não poderão ser resolvidos de modo linear e simplista.

\section{REFERÊNCIAS}

DELMAS-MARTY, Mireille. Três desafios para um Direito Mundial. Tradução de Fauzi Hassan Choukr. Rio de Janeiro: Lumen Juris Editora, 2003.

DESCARTES, René. Discurso do método. Tradução de Maria Ermantina Galvão. São Paulo: Martins Fontes, 1996. 
HALL, Stuart. The question of cultural identity. In: NASH, Kate (ed.). Readings in contemporary political sociology.Oxford: Blackwell, 2000.

LUHMANN, Niklas. A posição dos tribunais no sistema jurídico. Revista da AJURIS. Porto Alegre, n. 49, ano XVII, p. 149-168, jul. 1990.

El derecho de la sociedad. Tradução para o espanhol de Javier Torres Nafarrate, com colaboração de BrunhildeErker, Silvia Pappe e Luis Felipe Segura. 2. ed. Cidade do México: Herder, UniversidadIberoamericana, 2005.

. Globalization or world society: how to conceive of modern society? International Review of Sociology, [S. 1.], v. 7 n. 1, p. 67-79, mar.1997.

La sociedad de la sociedad. Tradução de Javier Torres Nafarrate. México: Herder, 2007.

. Law as a social system.Tradução para o inglês de Klaus A. Ziegert. New York: Oxford University Press, 2004.

. The world society as a social system. In: LUHMANN, Niklas: Essays on self reference. New York: Columbia UniversityPress, 1990.

; DE GIORGI, Rafaelle. Teoría dellasocietà. 8. ed. Milano: Franco Angeli, 1996.

NAFARRATE, Javier Torres. Luhmann: la política como sistema. México: Universidad Iberoamericana; Facultad de Ciencias Políticas y Sociales, UNAM, FCE, 2004.

NEVES, Marcelo. Entre Têmis e Leviatã: uma relação difícil - o Estado democrático de Direito a partir e além de Luhmann e Habermas. São Paulo: Martins Fontes, 2006.

. Transconstitucionalismo. São Paulo: Editora WMF Martins Fontes, 2009.

ROCHA, Leonel Severo. Da epistemologia jurídica normativista ao construtivismo sistêmico. In: ROCHA, Leonel Severo (Org.). Introdução à teoria autopoiética do sistema do Direito. $2^{\mathrm{a}}$ edição, revista e ampliada. Porto Alegre: Livraria do Advogado Editora, 2013.

. Epistemologia jurídica e democracia. 2. ed. São Leopoldo: Editora Unisinos, 2003.

. Observações sobre a observação Luhmanniana. In: ROCHA, Leonel Severo; KING, Michael; SCHWARTZ, Germano. A verdade sobre a autopoiese no Direito. Porto Alegre: Livraria do Advogado Editora, 2009. 
Três Matrizes da Teoria Jurídica. Constituição, Sistemas Sociais e Hermenêutica. Programa de Pós-Graduação em Direito da UNISINOS: mestrado e doutorado. Porto Alegre; São Leopoldo, p. 121-136, 1999.

; ATZ, Ana Paula. Do pluralismo jurídico ao diálogo inter-sistêmico das fontes na sociedade mundial. In: PEREIRA, Agostinho OliKoppe; HORN, Luiz Fernando Del Rio (Orgs.). Relações de consumo: globalização. Caxias do Sul: Educs, 2010, p. 107-132.

TEUBNER, Gunther.Autoconstitucionalização de corporações transnacionais? Sobre a conexão entre os códigos de conduta corporativos (Corporate CodesofConduct) privados e estatais. Tradução de Ivar Hartmann. Revisão de Germano Schwartz. In SCHWARTZ, Germano (Org.). Juridicização das esferas e fragmentação do direito na sociedade contemporânea. Porto Alegre: Livraria do Advogado Editora, 2012.

. Direito, sistema e policontexturalidade. Piracicaba: Unimep, 2005.

. El derecho como sistema autopoiético de la sociedad global. Tradução para o espanhol de Manuel CancioMeliá e Carlos Gómez-JaraDíez. Peru: ARA, 2005.

O direito como sistema autopoiético. Lisboa: Fundação CalousteGulbenkian, 1989. 